\title{
Effect of carbon fiber content on mechanical and tribological properties of carbon/phenolic resin composites
}

\author{
Midan $\mathrm{LI}^{1,2, a}$, Ruiying $\mathrm{Luo}^{1}$ \\ ${ }^{1}$ School of Physics and Nuclear Energy Engineering, Beijing University of Aeronautics and \\ Astronautics, No. 37, Xue Yuan Road, Hai Dian District, Beijing 100191, PR China \\ ${ }^{2}$ Beijing Institute of Graphic Communication, No. 25, Xinghua North Road, Da Xing District, Beijing \\ 102600, PR China \\ aemail: Imdjerry@sina.com
}

Keywords: Composites; Carbon Fiber; Impact Strength; Friction Coefficient; Wear Rate

\begin{abstract}
Composites made from phenolic resin are filled with natural graphite powders and carbon fibers were prepared through hot compression molding. Effects of carbon fiber content on the mechanical and tribological properties were investigated. The results indicated that the impact strength increased, friction coefficient changed slightly and wear rate of composites decreased with increasing carbon fiber content from $1 \mathrm{wt} \%$ to $5 \mathrm{wt} \%$, further increasing fiber content the impact strength and wear resistance of composites declined which were due to the aggregations of fibers leading to the weak grain boundary strength. The hardness increases continuously with increasing carbon fiber content.
\end{abstract}

\section{Introduction}

Carbon fiber reinforced polymer composites combine excellent mechanical and tribological properties. They have been emerging as attractive materials in a wide variety of applications, such as automotive, bearings, aerospace materials and railway transport systems [1-3]. Up to now, more and more researchers have focused on carbon fiber reinforced polymer composites. Zhang [4] developed short carbon fiber/PTFE/graphite filled PEEK composite and studied the effects of fiber orientation and nominal contact pressure on tribological properties. Bal [5] developed carbon nanofiber/epoxy composites and flexural modulus and hardness were found to increase significantly due to the addition of carbon nanofiber.

In this manuscript, carbon fiber was introduced to the graphite/phenolic resin composite prepared through a simple and low-cost hot compression molding. Meanwhile, the effects of carbon fiber content on mechanical and tribological properties of copper-carbon composites were investigated experimentally. Some composites were analyzed by SEM technique in order to evaluate the morphological characteristics of the fractured surfaces of composite.

\section{Experimental}

Materials. Graphite (average particle size $4 \mu \mathrm{m}$ ) with flake shape was used for base material. Graphite herein acted as the solid lubricant. Polyacrylonitrile (PAN) based carbon fiber (T300) of diameter $7.2 \mu \mathrm{m}$ and nominal length $4 \mathrm{~mm}$ was chosen as the reinforcement and phenolic resin as the binder.

Sample preparation. All components were mixed in a mechanical mixer for $10 \mathrm{~min}$ at 3000 rpm speed, and then spread in a metal mould. The mould was placed on flat plate sulfuration bed and heated to $180{ }^{\circ} \mathrm{C}$. A pressure of $20 \mathrm{MPa}$ was applied and held for $1.5 \mathrm{~h}$ to fabricate the composite. After the mould was cooled at room temperature, the sample was pulled off from the mould.

Characterization techniques. Tribological properties of composites were characterized using a block-on-ring tribometer under dry sliding condition. The samples have the form of cubic blocks of $10 \mathrm{~mm} \times 10 \mathrm{~mm} \times 10 \mathrm{~mm}$. The counter-face material was a hardened steel ring with the outer diameter 
of $45 \mathrm{~mm}$ and the thickness of $6 \mathrm{~mm}$. The normal load was $150 \mathrm{~N}$ and the rotating speed of the steel ring was $400 \mathrm{rpm}$. A Shore hardness tester (HS-19GDV) was used to measure the hardness of each sample using a $36.2 \mathrm{~g}$ diamond ball and dropping height was $19.0 \mathrm{~mm}$. The impact strength of composites was determined by means of drop-weight impact test as specified in GB/T 13465.4-2002. The hardness test samples were $20 \mathrm{~mm} \times 20 \mathrm{~mm} \times 10 \mathrm{~mm}$ in size, and the impact test samples were $10 \mathrm{~mm} \times 10 \mathrm{~mm} \times 60 \mathrm{~mm}$ in size. Morphological observation was performed on a Hitachi S4800 field-emitting scanning electron microscope. Prior to morphological observation, the surfaces of composite samples were vacuum-coated with a thin gold layer to avoid charging.

\section{Results and discussion}

Effect of carbon fiber content on impact strength of composite. To study the effect of carbon fiber on the properties of material, four different contents, $1 \%, 3 \%, 5 \%$ and $7 \%$ weight percent of carbon fiber were selected to prepare the composites. The dependence of impact strength on carbon fiber content for carbon/phenolic resin composites is displayed in Fig. 1. It is seen that the impact strength of composites increased from 0.14 to $0.82 \mathrm{~J} / \mathrm{cm}^{2}$ with increasing carbon fiber content from $1 \mathrm{wt} \%$ up to $5 \mathrm{wt} \%$, showing significant enhance effect on impact strength of composites. Thereafter, with further increasing carbon fiber content, the impact strength of composites decreased.

The carbon fiber is dispersed uniformly in the composite when carbon fiber content is less than $5 \mathrm{wt} \%$ (shown in Fig. 3a). During impacting process, when crack spreads in composites, it need to overcome resistance to through grain boundaries in the matrix, and then crack extends along fiber/matrix interface and overcomes the interfacial shear resistance to make the fibers debond, fracture and pull-out. This consumed more fracture energy and increased the impact strength of composite accordingly.

The carbon fiber with small diameter has large surface area and easy to aggregate. The higher the fiber content, the more difficult to disperse uniformly in the matrix. Fig. 3b shows that the SEM images of fractured surface of composites with $7 \mathrm{wt} \%$ carbon fiber. It can be seen that carbon fiber aggregated inside the composite. The aggregations of fiber at high content weaken the bond strength of fiber/matrix interface, and then weaken the energy consumption ability of carbon fibers which consume fracture energy by fiber debond and pull out, ultimately resulting in the decrease of impact strength.

Effect of carbon fiber content on hardness of composite. Fig. 2 shows the hardness of the composite as a function of carbon fiber content. With increasing carbon fiber content, the hardness increases continuously. Carbon fibers have a higher hardness compared with graphite, thus the carbon fiber content increases, the hardness of the composite increases.

Effect of carbon fiber content on friction coefficient and wear rate of composite. Fig. 4 and Fig. 5 show the relationship between carbon fiber content and friction coefficient and wear rate of the composites during sliding. The friction coefficient changes slightly with increasing fiber content from $1 \mathrm{wt} \%$ to $5 \mathrm{wt} \%$. Above $5 \mathrm{wt} \%$ fiber content, the friction coefficient goes up with further increasing content of carbon fibers to $7 \mathrm{wt} \%$. Both graphite and carbon fibers possess self-lubricating characteristics, so the changes in carbon fiber content have little effect on the friction coefficient. However, the poor bond strength attributed to aggregations of fiber at high content leads to carbon fiber losing off from the matrix and becoming wear debris, which resulting in the tribosurface of the composite roughening. Thus the friction coefficient increased at $7 \mathrm{wt} \%$ fiber content. 


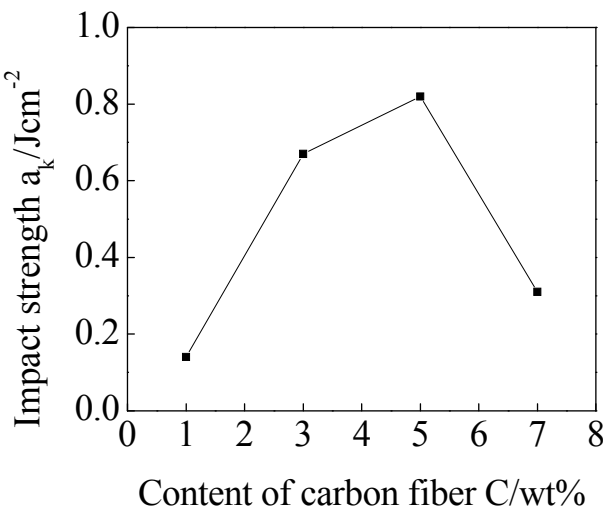

Fig. 1 Effect of the content of carbon fiber on the impact strength of composites.

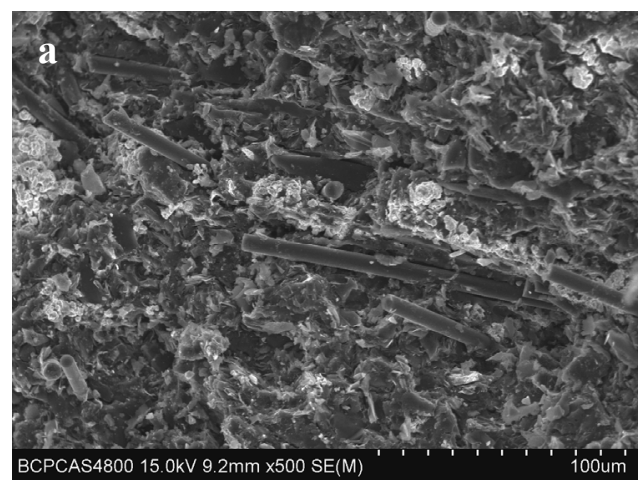

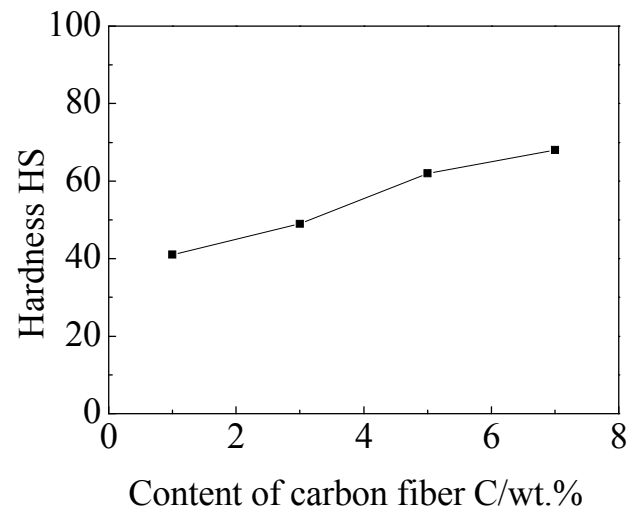

Fig. 2 Effect of the content of carbon fiber on the wear rate of composites.

Fig. 3 SEM images of the fracture surface of composites prepared with $5 \mathrm{wt} \%$ carbon fiber (a) and $7 \mathrm{wt} \%$ carbon fiber (b).

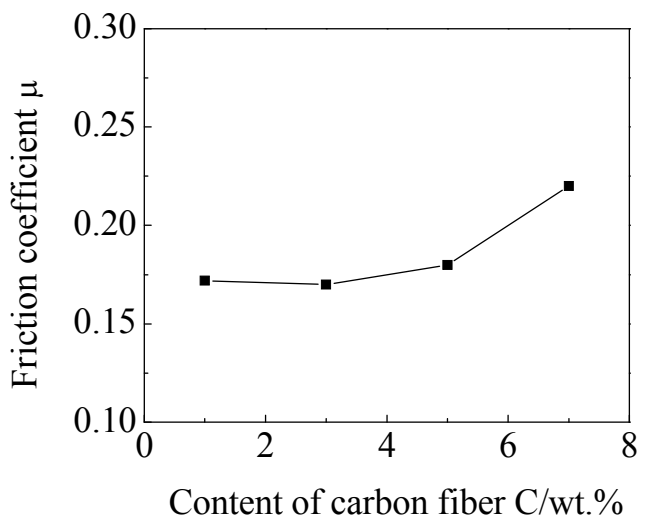

Fig. 4 Effect of the content of carbon fiber on the friction coefficient of composites.
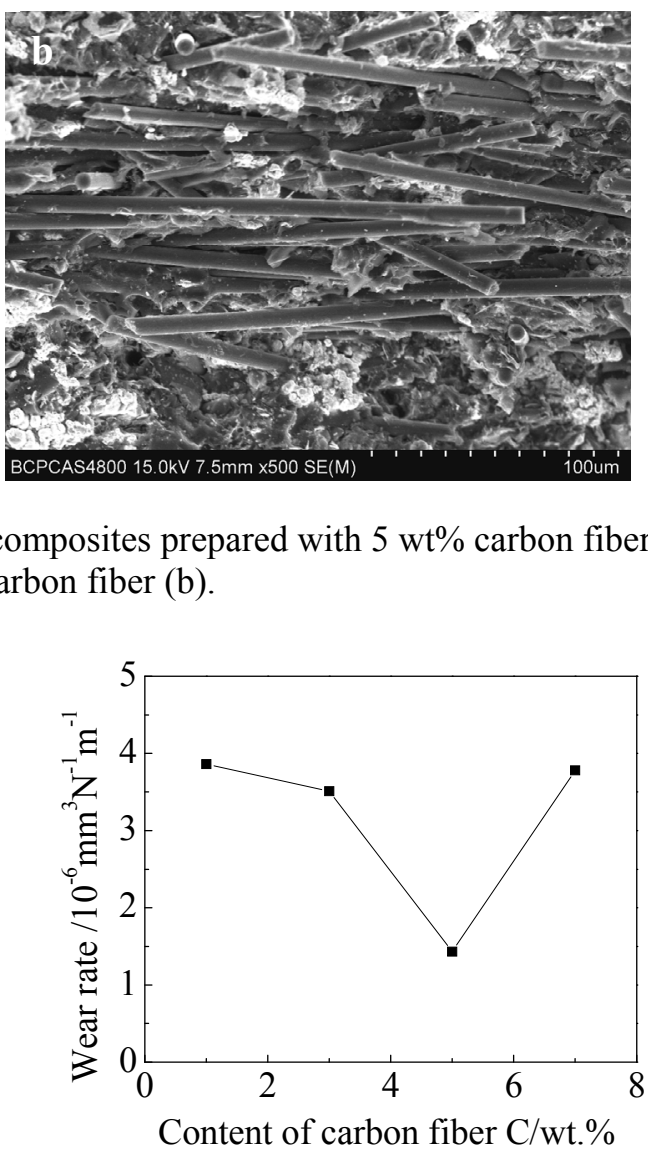

Fig. 5 Effect of the content of carbon fiber on the wear rate of composites.

The wear rate decreased with increasing fiber content. The minimum values is $1.43 \times 10^{-6}$ $\mathrm{mm}^{3} \mathrm{~N}^{-1} \mathrm{~m}^{-1}$ for $5 \mathrm{wt} \%$ carbon fibers addition. The good solid lubrication effect of the carbon fibers restricted the increasing of contact stress during sliding conditions and decreased the wear rate of the composites [6]. Further, the enhancement effect of the short carbon fiber hinder the generation and propagation of the cracks of the composite and raised the toughness of the composite, and then reduced the amount of wear debris and ultimately improved the wear resistance of the composites. 


\section{Conclusion}

Carbon/phenolic resin composites were prepared through simple and low-cost hot-compression molding. The introduction of carbon fiber into composite results in an increase in impact strength such that impact strength of composite with $5 \mathrm{wt} \%$ carbon fiber increases by 4.8 times comparing with $1 \mathrm{wt} \%$ of composite. In the range of $1-5 \mathrm{wt} \%$ carbon fiber, the friction coefficient changes slightly and the wear rate decreased with increasing fiber content. Above $5 \mathrm{wt} \%$, the friction coefficient and wear rate go up with further increasing fiber content which were due to the aggregations of fibers leading to the weak grain boundary strength.

\section{References}

[1] Yasar I, Canakci A, Arslan F. The effect of brush spring pressure on the wear behaviour of copper-graphite brushes with electrical current [J]. Tribology International, 200740 (9) 1381-1386.

[2] Jianxin Wang, Ruijun Zhang, Jiang $\mathrm{Xu}$, Chao $\mathrm{Wu}$, Peng Chen. Effect of the content of ball-milled expanded graphite on the bending and tribological properties of copper-graphite composites [J]. Materials and Design, 201347 667-671.

[3] X.C. Ma, G.Q. He, D.H. He, C.S. Chen, Z.F. Hu. Sliding wear behaviour of copper-graphite composite material for use in maglev transportation system [J]. Wear, 2008265 (7-8) 1087-1092.

[4] G. Zhang, Z. Rasheva, A.K. Schlarb. Friction and wear variations of short carbon fiber (SCF)/PTFE/graphite (10 vol.\%) filled PEEK: Effects of fiber orientation and nominal contact pressure [J]. Wear, 2010268 (7-8) 893-899.

[5] Smrutisikha Bal. Experimental study of mechanical and electrical properties of carbon nanofiber/epoxy composites [J]. Materials and Design, 201031 (5) 2406-2413.

[6] H. L. Tang, X. R. Zeng, X. B. Xiong, Long Li. Mechanical and tribological properties of short-fiber-reinforced SiC composites [J]. Tribology International, 2009, 42 (6) 823-827. 